\title{
Hyperoxic boundary layers inhabited by the epiphytic meiofauna of Fucus serratus
}

\author{
Sandra Irwin*, John Davenport \\ Department of Zoology and Animal Ecology and Environmental Research Institute, University College Cork, Lee Maltings, \\ Prospect Row, Cork, Ireland
}

\begin{abstract}
Opto-chemical microsensors were used to gather information about oxygen levels close to the thallus surface of Fucus serratus L. Oxygen tensions as high as $560 \%$ air saturation were recorded at the seaweed surface in seawater under static conditions at a light intensity of $229.5 \mu \mathrm{mol}$ photon $\mathrm{m}^{-2} \mathrm{~s}^{-1}$. This level of oxygen supersaturation was restricted to a thin layer directly above the seaweed surface and a steep oxygen gradient was observed through the boundary layer, which extended to a distance of 1 to $2 \mathrm{~mm}$ in a static water body. Although remaining considerably elevated relative to the oxygen tension in the surrounding water, oxygen tensions at the seaweed surface were reduced under flow conditions. The thickness of the oxygen-supersaturated boundary layer decreased to less than $1 \mathrm{~mm}$ under flow conditions. However, flow rate itself did not have a significant effect on oxygen tensions at the seaweed surface or on the depth of the boundary layer. A rapid reaction of oxygen tension within the boundary layer was observed in response to initiation or cessation of flow. In darkness, under static conditions, the oxygen tension at the seaweed surface decreased to as little as $40 \%$ air saturation. Under these conditions, oxygen tension increased through the boundary layer, reaching levels similar to the surrounding water in less than $1 \mathrm{~mm}$. These data indicate that small epiphytic animals (copepods, nematodes etc.) encounter highly hyperoxic conditions during daytime, even when there is water flow over seaweed. They are therefore exposed to the possibility of hyperoxic/free radical damage, even though living in an apparently benign environment.
\end{abstract}

KEY WORDS: Fucus serratus · Microelectrode · Oxygen micro-gradient · Hyperoxia · Boundary layer · Epiphytic meiofauna

Resale or republication not permitted without written consent of the publisher

\section{INTRODUCTION}

Marine and freshwaters are often considered low oxygen environments when compared with the atmosphere. Fluctuations in oxygen tensions in aquatic environments are well documented (Wiebe 1933, Stephenson et al. 1934, Daniel \& Boyden 1975, Salvato et al. 2001). Oxygen levels change due to the imbalance between photosynthesis and respiration, and are also affected by temperature and salinity. Oxygen gradients occur in water due to the slow diffusion of oxygen, a phenomenon that is particularly evident in shallow environments (Gooday et al. 2001, Neira et al.

*Email: s.irwin@ucc.ie
2001). Boundary layers develop over stationary objects in moving water, where flow velocity decreases towards the solid-fluid interface leading to gradients of environmental parameters within layers. The impact of such gross flow gradients on organisms in aquatic systems is well documented (Kaspar 1992, Searcy-Bernal 1996), yet little attention has been focussed on oxygen micro-gradients that may occur in the diffusive boundary layer close to the surface of a photosynthesising plant in a water body.

The intertidal fucoid seaweed Fucus serratus L. is a dominant low shore seaweed commonly found on temperate northeast Atlantic shores. F. serratus provides a diverse range of niches exploited by an array of epiphytic meiofauna, with over 90 taxa being recorded on this particular seaweed (Boaden et al. 1975). The epi- 
phytic meiofaunal assemblage is dynamic and there is evidence of both temporal and spatial partitioning amongst species (Boaden 1996, Williams 1996) that depend on the range of habitats provided by $F$. serratus for feeding, reproduction and avoidance of predation and adverse conditions (Alldredge \& King 1980). Some species are seasonal dwellers on $F$. serratus plants (Kain \& Svendsen 1979, Crothers 1985), while others are known to remain through all of their life history stages (Williams 1992).

Seaweeds with planar thalli such as Fucus serratus are known to have higher photosynthetic productivity than branched forms. The vegetative thallus of $F$. serratus, in particular, has a high photosynthetic capacity; in contrast, that of the receptacle tissue is approximately $50 \%$ lower. While neither show seasonal variation (Brenchley et al. 1997), the relationship between light intensity and photosynthetic rate is seasonal and a marked reduction in light compensation point is seen in winter (King \& Schramm 1976). Conversely, respiratory rate has been shown to vary seasonally and to be unaffected by reproductive development (Brenchley et al. 1997).

The development in recent years of microoptodes for oxygen measurement has been directed primarily at studying oxygen levels in sediments (e.g. Jørgensen \& Des Marais 1990, Wenzhofer et al. 2001). Opto-chemical microsensors allow measurement of chemical parameters with high spatial and temporal resolution and with negligible disturbance of the microenvironment in natural systems (Holst et al. 1997). Such devices also have potential as tools for studying microhabitats within or around living organisms in aquatic systems (Kaspar 1992, Lassen et al. 1994, Fernandez et al. 2000), not only as a result of their small size, but also as stirring is not required to obtain accurate readings.

Seaweeds are often subjected to hypoxia, particularly in the dark (Barinov et al. 1998), thus imposing hypoxic conditions on their epiphytic associates. As with all photosynthetic organisms, seaweeds are subject to reactive oxygen production (Collén \& Davison 1999b, Rijstenbil et al. 2000), yet there have been no investigations of the potentially hyperoxic conditions that would be expected close to photosynthesising seaweeds. This study was designed to test 2 hypotheses: (1) that hyperoxic layers develop close to thalli of Fucus serratus and persist under conditions of flow; and (2) that the meiofaunal organisms associated with F. serratus are of a size that makes them likely to be exposed to hyperoxia.

\section{MATERIALS AND METHODS}

Sample collection. All experimental material was collected from Fountainstown, a rocky beach on the south coast of Ireland $\left(51^{\circ} 46^{\prime} \mathrm{N}, 8^{\circ} 18^{\prime} \mathrm{W}\right)$ on 8 separate occasions between December 2000 and July 2001. The vegetation at this site is dominated by Fucus spp. For oxygen level studies, randomly selected individual plants of the intertidal brown fucoid seaweed Fucus serratus were removed from the shore at a water depth of less than $0.5 \mathrm{~m}$ during the hour immediately preceding low tide. Plants were collected in polyethylene bags in seawater from the local environment and returned to the laboratory where they were maintained in aerated seawater for up to $18 \mathrm{~h}$ prior to experimentation. Hooper (2002) has demonstrated that the most common epifaunal groups are present throughout day/night and tidal cycles.

Meiofaunal morphology. For examination of the fauna associated with Fucus serratus, individual plants were collected on the same 8 occasions using the method described by Davenport et al. (1996). A polyethylene bag was placed over the entire plant underwater and then sealed around the base of the plant before cutting the holdfast and gently removing it from the water. Animals were removed from the seaweed using $60 \%$ alcohol in seawater. The plants were then shaken vigorously and the seawater collected in each bag sieved using a $64 \mu \mathrm{m}$ plastic sieve and the contents returned to the sample bag containing the seaweed plant by means of reverse sieving using fresh seawater. On return to the laboratory, Rose Bengal dye (Sigma) was added to the contents of each bag to promote visibility of organisms and these were allowed to rest overnight. The fluid from each sample bag was subsequently sieved using a $64 \mu \mathrm{m}$ sieve and the bag repeatedly washed out with seawater, all of which was passed through the same sieve. The final contents of the sieve were then examined under a binocular microscope and organisms stored in $60 \%$ alcohol in seawater. Within $24 \mathrm{~h}$, individual animals were identified to higher taxon level as described by Davenport et al. (1999), and both length and width were measured using a light microscope fitted with an eyepiece graticule. In total, from the 8 sampling occasions, the longest and shortest axes of 66 animals were measured.

Oxygen measurement. Oxygen measurements were carried out using optical chemical fibre microsensors and the MICROX 1 portable optical oxygen measuring system (Precision Sensing). These microoptodes measure luminescence of an immobilised luminophore mounted in thin optical fibre $(<50 \mu \mathrm{m})$. The luminescence is quenched by molecular oxygen and there is a predictable relationship between the 2 quantities. There is no consumption of oxygen by the probe and oxygen records are unaffected by microbending of the fibre tip, or the turbidity, refractive index or coloration of the solution being sampled, and full response time is quick ( $<5 \mathrm{~s})$, irrespective of temperature (Klimant et al. 
1995, Holst et al. 1997). During operation, recordings of oxygen as \% air saturation are made at $1 \mathrm{~s}$ intervals and data sets are continuously transmitted via the serial interface of a PC, allowing instant recording and storing using dedicated data handling and storage software. Type A microoptodes (measuring range from 0 to $800 \%$ air saturation) were employed. These are based on a modified RuDPP dye, and the correlation factor of the calibration curve in the MICROX 1 and empirical data measured in a precise gas mixing device is 0.99998 . Measurement of the microoptodes against a precise gas mixing device (mechanical Vosthofpump, $0.1 \%$ accuracy) shows that a 2 point calibration procedure $(0$ and $100 \%$ air saturation $)$ describes the calibration curve sufficiently in the range from 0 to $100 \%$ oxygen (\% volume) (0 to $500 \%$ air saturation) with no significant offset to be considered (Holst et al. 2000). This was verified in the laboratory where a 2-point calibration was carried out and the MICROX used to measure oxygen in water that had been purged with $100 \%$ oxygen gas in a capped flask (to prevent air from entering the gas phase of the flask) with a small hole to prevent an increase in pressure $(473.5 \pm 3.9 \%)$.

Oxygen measurements were performed within $18 \mathrm{~h}$ of collection of Fucus serratus. Prior to each measurement session a 2 point calibration of the microsensor was carried out using air saturated $(100 \%$ air saturation) and oxygen free ( $0 \%$ air saturation) water, the latter obtained by bubbling oxygen-free nitrogen through seawater. Individual fronds of $F$. serratus were removed and attached to a stable panel in a seawater flow chamber. Water was recirculated through this chamber from a storage vessel by means of a small centrifugal pump and the flow rate was controlled using a series of valves. Seawater temperature was maintained during the experimental period by submerging the water storage vessel in a water bath. Artificial lights mounted above the experimental vessel provided illumination and light intensity was measured using a Stix631 lightmeter. The microsensor was housed in a steel needle and was mounted over the seawater flow chamber using a micromanipulator (Sutter Instrument) supported by a magnetic stand. The sensor tip was manipulated into position using the micromanipulator, calibrated at $10 \mu \mathrm{m}$ intervals in the vertical plane with the aid of a binocular microscope. A second steel needle, similar to that of the sensor housing was placed against the seaweed surface in close proximity to the sensor tip, as this was seen in preliminary trials to prevent the build up of gas bubbles on the sensor tip.

Oxygen gradients close to the thallus surface were investigated by measuring oxygen at the seaweed surface, and at intervals of $0.2 \mathrm{~mm}$ from the surface in the vertical plane, directly above the seaweed. Recordings were made in each position for 1 min, giving 60 measurements, the first and last 10 of which were discarded. This resulted in a total of 40 values for each sensor position. Measurements were carried out under static conditions on a total of 7 occasions. On each occasion, readings were made while the sensor was moved away from the seaweed surface and once again as the sensor was moved towards the surface. To investigate the speed of response to initiation and cessation of flow in the water body above the seaweed, the sensor was placed against the seaweed thallus and recordings of oxygen tension made continuously as flow and static conditions were alternated. Measurements of oxygen gradients close to the thallus surface, as described above, were repeated under 2 flow conditions, 137 and $276 \mathrm{~cm} \mathrm{~min}^{-1}$ (averaged over the crosssectional area of the flow chamber) at a light intensity of $229.5 \mu \mathrm{mol}$ photons $\mathrm{m}^{-2} \mathrm{~s}^{-1}$ and also in darkness. Light intensity varies considerably in nature from extremely bright conditions to complete darkness, and light saturation is considered to be as high as $2000 \mu \mathrm{mol}$ photons $\mathrm{m}^{-2} \mathrm{~s}^{-1}$ (Collén \& Davison 1999a,b).

All data are reported as means $\pm \mathrm{SD}$. One-way ANOVA, following Levenes $F$-test for homogeneity of variance, was used to identify significant differences amongst treatment groups.

\section{RESULTS}

\section{Epiphytic meiofauna}

The most common meiofauna collected were marine harpacticoid copepods, and the remainder consisted primarily of marine mites (Rhombognathides pascens), foraminifera and annelids (Fig. 1). A number of unidentified eggs were also found and the diameters of a

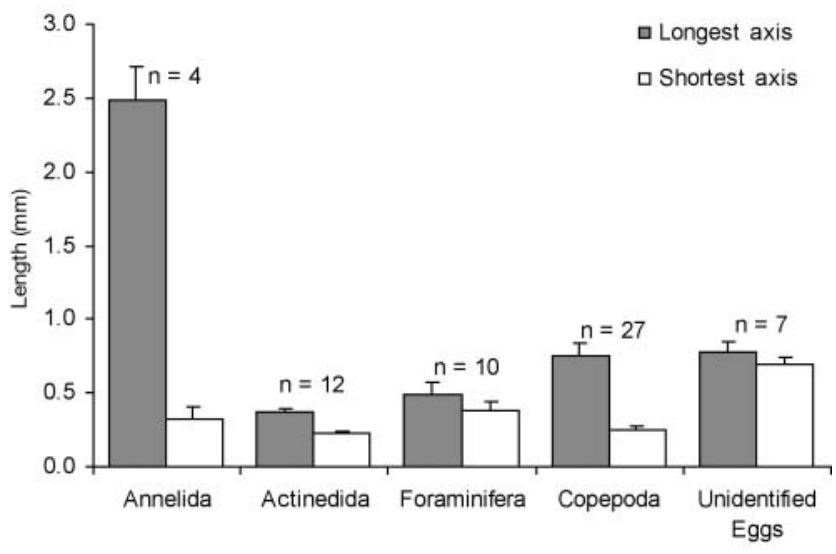

Fig. 1. Fucus serratus. Mean $( \pm \mathrm{SD})$ length of the longest and shortest axes of epiphytic meiofaunal animals collected from 8 plants at Fountainstown on the south coast of Ireland 


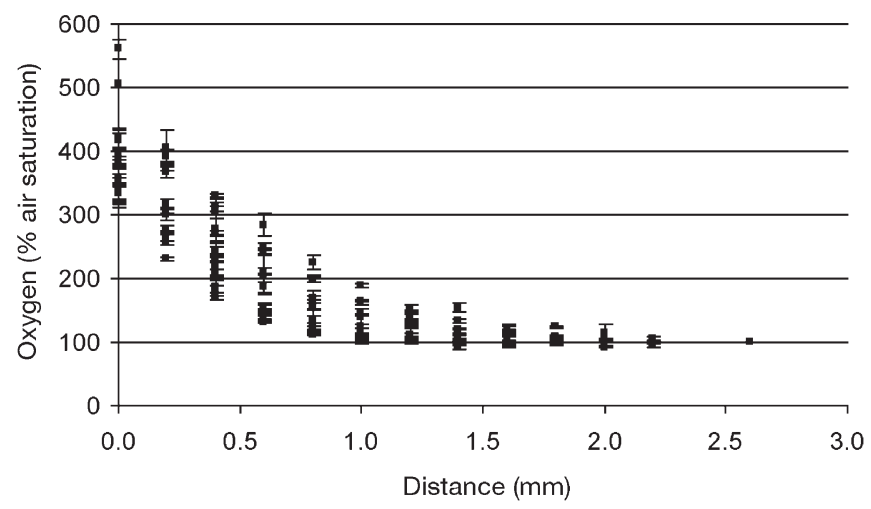

Fig. 2. Fucus serratus. Mean $( \pm \mathrm{SD})$ oxygen concentration $(\%$ air saturation) at distances less than $3 \mathrm{~mm}$ from the surface of thalli under static conditions at an average light intensity of $229.5 \mu \mathrm{mol}$ photons $\mathrm{m}^{-2} \mathrm{~s}^{-1}$ at the surface $(\mathrm{n}=7)$

(A)

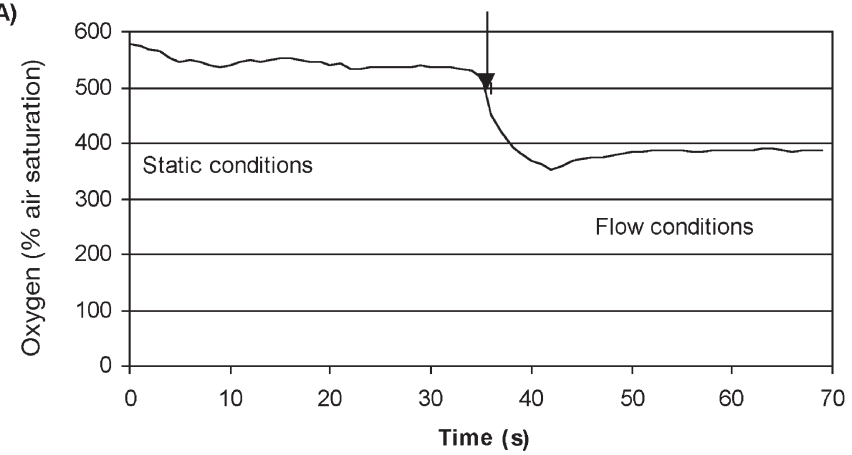

(B)

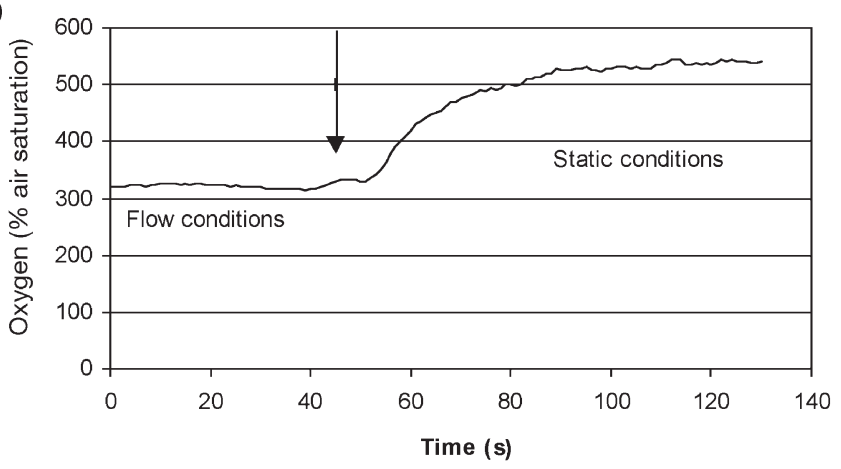

Fig. 3. Fucus serratus. Effect of seawater flow on the oxygen concentration (\% air saturation) at the surface of a thallus. Arrows indication initiation and cessation of flow in (A) and (B), respectively

representative sample of these were measured. The results show that, with the exception of the annelids, the average length of all animals living on this seaweed was less than $1 \mathrm{~mm}$ and most had a body thickness well below $0.5 \mathrm{~mm}$. Although the mean length of the annelids was $2.5 \pm 0.2 \mathrm{~mm}$, the average recorded body thickness was only $0.3 \pm 0.1 \mathrm{~mm}$.

\section{Oxygen micro-gradients}

Under static conditions, at a light intensity at the seaweed surface of $229.5 \mu \mathrm{mol}$ photons $\mathrm{m}^{-2} \mathrm{~s}^{-1}$, the maximum recorded oxygen tension, when the microsensor tip was positioned against the surface of a thallus of Fucus serratus, was $560 \%$ air saturation, and the lowest recorded was $320 \%$ air saturation. A steeply decreasing oxygen concentration gradient was observed with distance away from the thallus surface in the vertical plane (Fig. 2). The relationship between oxygen levels and distance from the seaweed surface was steeply curvilinear, levelling off 1.0 to $1.5 \mathrm{~mm}$ from the seaweed surface. Although the range of oxygen levels from independent sampling days showed some variation, levels generally did not fall as low as those found in the water column until at least $1 \mathrm{~mm}$ from the seaweed surface, and on occasion remained elevated to a distance of $2 \mathrm{~mm}$. Oxygen tensions higher than that of the water column were not recorded farther than $2 \mathrm{~mm}$ from the seaweed surface on any occasion.

The initiation of flow in the water body led to a sharp decrease in oxygen concentration at the seaweed surface, although it was not reduced to that of the water column (Fig. 3). The observed drop in oxygen tension was very rapid and was completed within about $10 \mathrm{~s}$, after which the oxygen tension stabilised and no further reduction was observed. Under reverse conditions, when oxygen was continuously monitored at the seaweed surface in a flowing water body, cessation of flow led to an increase in oxygen at the surface. In this case, however, the duration of the transition period was longer and stabilisation of the oxygen tension was not achieved for over $1 \mathrm{~min}$.

When seawater flow was introduced to the water body around the Fucus serratus thallus in the experimental chamber, the average recorded oxygen tension at the thallus surface decreased (Fig. 4). The maximum average concentrations recorded were 362 and $340 \%$ air saturation, at average flow rates of 137 and $276 \mathrm{~cm} \mathrm{~min}^{-1}$, respectively. Steep oxygen micro-gradients were again observed in the vertical plane away from the seaweed. In a flowing water body, the depth of the hyperoxic boundary layer was reduced (Fig. 4). When the effects of zero, low and high flows were investigated using a 1-way ANOVA, significant variation in oxygen tensions was detected at distances less than $1.0 \mathrm{~mm}$ from the frond surface. Tukey's post hoc test revealed that there was no difference in oxygen tensions between flow rates, but that the difference existed between oxygen tensions in static conditions and both flow conditions. Oxygen tensions in static conditions were significantly higher than those in flow conditions at positions less than $1.0 \mathrm{~mm}$ from the seaweed surface (Table 1), indicating a significant effect of flow on oxygen levels within boundary layers. 


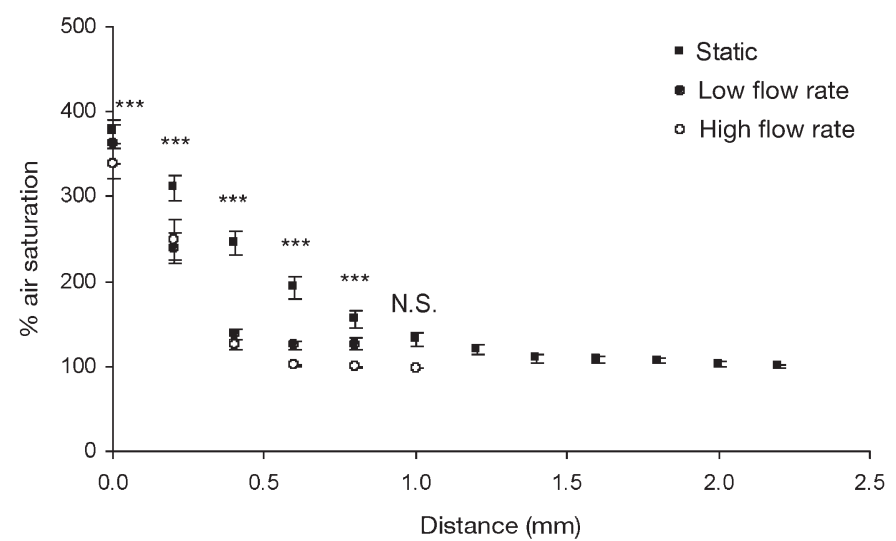

Fig. 4. Fucus serratus. Mean $( \pm \mathrm{SD})$ oxygen concentration (\% air saturation) at $0.2 \mathrm{~mm}$ increments in the vertical plane above thalli at an average light intensity of $229.5 \mu \mathrm{mol}$ photons $\mathrm{m}^{-2} \mathrm{~s}^{-1}$ under static conditions and at 2 flow rates, a low flow rate of $137 \mathrm{~cm} \mathrm{~min}^{-1}(\mathrm{n}=7)$ and a high flow rate of $276 \mathrm{~cm} \mathrm{~min}^{-1}(\mathrm{n}=6)$. Statistical significance of ANOVA tests: ${ }^{* * *} \mathrm{p}<0.001$, ns: not significant

The average oxygen tension at the seaweed surface in darkness was $68.6 \pm 12.2 \%$ air saturation. In all cases, oxygen gradients were reversed in darkness when compared with illuminated conditions (Fig. 5). Oxygen concentrations increased rapidly with distance from the seaweed surface towards values recorded in the water column, which remained largely unaffected by illumination.

\section{DISCUSSION}

The development of microsensors for oxygen has enabled investigation of the microenvironment within boundary layers next to solid structures immersed in bodies of liquid. Work in this area has focussed on sediment (e.g. Jørgensen \& Des Marais 1990, Holst et al. 1997, Wenzhöfer et al. 2001), but has also included some investigations of boundary layers adjacent to aquatic plants and animals (e.g. Searcy-Bernal 1996, Rink et al. 1998, Ploug et al. 1999, Kohler-Rink \& Kuhl 2000). These microenvironments, which are home to a diverse array of meiofauna, are now being described for the first time. Oxygen boundary layers described in the literature are of the order of $2 \mathrm{~mm}$ and are dependent on a number of environmental factors (Jørgensen \& Des Marais 1990, Searcy-Bernal 1996, Ploug et al. 1999, Kohler-Rink \& Kuhl 2000).

This study describes, for the first time, zones of dramatic oxygen flux close to fronds of Fucus serratus (Fig. 2). The zones have depths greater than the maximum size of the meiofauna that inhabit the surface of this particular seaweed, even under flowing conditions. In this study, the maximum boundary layer
Table 1. Fucus serratus. Results of 1-way ANOVAs on oxygen tensions at 3 flow rates $\left(0,137\right.$ and $\left.276 \mathrm{~cm} \mathrm{~min}^{-1}\right)$ at each of 6 distances from the thallus surface, ranging from touching the frond to $1.0 \mathrm{~mm}$ from the frond in the vertical plane. ns: not significant

\begin{tabular}{|lcc|}
\hline $\begin{array}{l}\text { Distance from } \\
\text { thallus surface }(\mathrm{mm})\end{array}$ & $F_{2,39}$ & $\mathrm{p}$ \\
\hline 0.0 & 3.21 & 0.05 \\
0.2 & 7.43 & $<0.001$ \\
0.4 & 33.51 & $<0.001$ \\
0.6 & 21.76 & $<0.001$ \\
0.8 & 7.83 & $<0.001$ \\
1 & 2.07 & $\mathrm{~ns}$ \\
\hline
\end{tabular}

depth, within which a steep oxygen gradient was recorded, in static water was $2 \mathrm{~mm}$, and oxygen levels were generally seen to level off between 1.0 and $1.5 \mathrm{~mm}$ from the surface of the $F$. serratus fronds. Steep oxygen gradients have previously been described around non-planar algae under static conditions (Lassen et al. 1994, Ploug et al. 1999, Pöhn et al. 2001) peaking at as much as $506 \%$ air saturation (Pöhn et al. 2001). Oxygen tensions as high as 360 to $562 \%$ air saturation were recorded in this study when the MICROX 1 sensor tip was positioned directly against the surface of the F. serratus fronds.

The depth of oxygen boundary layers recorded near Fucus serratus fronds in flowing water was reduced compared with those measured in still water. Nevertheless, steep oxygen gradients were maintained in proximity to the surface although the depth of the gradient zone was reduced (Fig 4). These findings are consistent with previous studies on similar systems

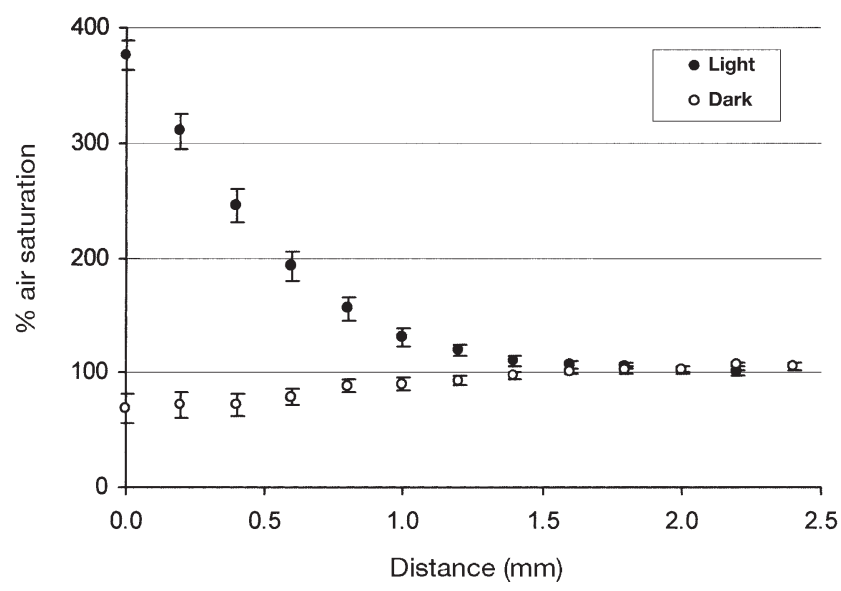

Fig. 5. Fucus serratus. Mean oxygen concentration $( \pm \mathrm{SD})$ at $0.2 \mathrm{~mm}$ increments in the vertical plane above thalli under static conditions at a light intensity of $229.5 \mu \mathrm{mol}$ photons $\mathrm{m}^{-2}$ $\mathrm{s}^{-1}(\mathrm{n}=7)$ and in darkness $(\mathrm{n}=3)$ 
where flow conditions reduce the depth of boundary layers relative to that measured under static conditions (Kaspar 1992, Zhang \& Bishop 1994, Searcy-Bernal 1996, Kohler-Rink \& Kuhl 2000). The response time of oxygen tension to changes in flow conditions was seen to be rapid, being completed in approximately 1 min.

It has previously been demonstrated that light intensity as well as flow rate can impact on oxygen levels within boundary layers, to varying degrees, in a range of systems (Kaspar 1992, Lassen et al. 1994, SearcyBernal 1996, Rink et al. 1998), with levels decreasing towards zero in complete darkness. In this study, a marked difference was seen in the oxygen profiles close to the seaweed surface under conditions of light and dark, and oxygen tensions as low as $40 \%$ air saturation were recorded at the seaweed surface.

Within the boundary layer described at the surface of the fronds, oxygen levels switch rapidly from hypoxic to hyperoxic, depending on the prevailing conditions of light intensity and flow velocity (e.g. Fig. 5). In the natural environment, it is unlikely that severe hypoxic stress ( $<40 \%$ air saturation) occurs at night, because the bulk of sea water in turbulent coastal waters is close to $100 \%$ air saturation. However, it is certain that the epiphytic meiofauna of Fucus serratus, as a consequence of their size, are regularly surrounded by oxygen-supersaturated water. In a study of oxygen gradients within tubes of Feldmania caespitula where oxygen tensions were seen to reach over $500 \%$ air saturation under static conditions, it was suggested that the observed fluctuations in oxygen tension might lead to temporal emigration of epiphytic species (Pöhn et al. 2001). This is not the case for F. serratus, which is known to have a substantial epiphytic meiofauna throughout day/night cycles (Hooper 2002). Meiofaunal animals are too small for measurements of the oxygen content of their internal milieu to be carried out using existing methods. Little attention has been paid to gaseous exchange in animals of this size, as they are all far smaller in thickness than the (approximately) $1 \mathrm{~mm}$ size at which diffusion becomes limiting (Krogh 1919, Alexander 1971) and it is generally accepted that respiratory pigments are absent in animals of this size. This may possibly reflect a lack of investigation, although there is experimental evidence that this is the case for harpacticoid copepods (McAllen et al. 1999). Due to their small size and integumental thickness, there will be a minimal barrier to inward diffusion of oxygen and they will behave virtually identically to the surrounding sea water, and are also likely to reach equilibrium in seconds/minutes.

Hyperoxic environments and their faunas have attracted little previous marine biological study. Striking diurnal variations in oxygen tension, between 3 and $300 \%$ air saturation, were reported from emersed intertidal rock pools that contained substantial quantities of macroalgae (Ganning 1971, Daniel \& Boyden 1975). However, though these workers drew attention to the problems of hypoxic survival for pool animals at night, hyperoxic stress has been largely ignored as a potential problem for some marine animals. Hyperoxic stress is associated with the excessive formation of reactive oxygen species (ROS) including hydrogen peroxide, hydroxyl radicals and superoxide radicals. ROS are normal products of aerobic metabolism and excess production is associated with photosynthetic organisms (Collén \& Davison 1999b, Rijstenbil et al. 2000). If not detoxified by enzymes such as superoxide dismutase and glutathione peroxidase, ROS can damage cellular lipids, proteins and nucleic acids (e.g. Halliwell \& Gutteridge 1989, Pouzand \& Tyrell 1999). Much consideration has been given to the development of hyperoxia in corals and sea anemones that have algal symbionts in their tissues (e.g. Harland \& Davies 1995), but research has tended to focus on the energetics of the dual organism systems (e.g. Gardella \& Edmunds 1999) rather than hyperoxic stress. An exception is an investigation of superoxide ion production in thermally stressed symbiotic sea anemones Aiptasia pulchella (Nii \& Muscatine 1997); however, in that case, the animal itself was producing the reactive species, rather than the symbionts. Our study suggests that general seaweed epiphytic faunas may be fruitful sources of further information about antioxidant defence systems.

Acknowledgements. The authors thank R. McNamara for valuable technical assistance.

\section{LITERATURE CITED}

Alexander RMcN (1971) Size and shape. Edward Arnold, London

Alldredge AL, King JM, (1980) Effects of moonlight on the vertical migration pattern of demersal zooplankton. J Exp Mar Biol Ecol 44:133-156

Barinov GV, Lopukhin AS, Trenckenshu RP (1998) Respiration energetics of marine algae for total heat production and some features of photosynthesis. Thermochim Acta 309:133-138

Boaden PJ (1996) Habitat provision for meiofauna by Fucus serratus epifauna with particular data on the flatworm Monoceis lineata. Mar Ecol 17:67-75

Boaden PJS, O'Connor RJ, Seed R (1975) The composition and zonation of a Fucus serratus L. community in Strangford Lough, Co. Down. J Exp Mar Biol Ecol 17:111-136

Brenchley JL, Raven JA, Johnston AM (1997) Resource acquisition in 2 intertidal fucoid seaweeds, Fucus serratus and Himanthalia elongata: seasonal variation and effects of reproductive development. Mar Biol 129:367-375

Collén J, Davison IR (1999a) Reactive oxygen production and damage in intertidal Fucus spp. (Phaeophyceae). J Phycol 35:54-61 
Collén J, Davison IR (1999b) Reactive oxygen metabolism in intertidal Fucus spp. (Phaeophyceae). J Phycol 35:62-69

Crothers JH (1985) Dog-whelks: an introduction to the biology of Nucella lapillus (L.). Field Stud 6:291-360

Daniel MJ, Boyden CR (1975) Diurnal variations in physicochemical conditions within intertidal rockpools. Field Stud 4:161-176

Davenport J, Pugh PJA, McKechnie J (1996) Mixed fractals and anisotropy in subantartic marine macroalgae from South Georgia: implications for epifaunal biomass and abundance. Mar Ecol Prog Ser 136:245-255

Davenport J, Butler A, Cheshire A (1999) Epifaunal composition and fractal dimensions of marine plants in relation to emersion. J Mar Biol Assoc UK 79:351-355

Fernandez M, Bock C, Portner HO (2000) The cost of being a caring mother: the ignored factor in the reproduction of marine invertebrates. Ecol Lett 3(6):487-494

Ganning B (1971) Studies on the chemical, physical and biological conditions in Swedish rockpool ecosystems. Ophelia 2:51-105

Gardella DJ, Edmunds PJ (1999) The oxygen microenvironment adjacent to the tissue of the scleractinian Dichoncoenia stokesii and its effect on symbiont metabolism. Mar Biol 135:289-295

Gooday AJ, Bernhard JM, Levin LA, Suhr SB (2001) Foraminifera in the Arabian Sea oxygen minimum zone and other oxygen-deficient settings: taxonomic composition, diversity, and relation to metazoan faunas. Deep-Sea Res II 47:25-54

Halliwell B, Gutteridge JMC (1989) Free radicals in biology and medicine, 2nd edn. Clarendon Press, Oxford, p 415

Harland AD, Davies PS (1995) Symbiont photosynthesis increases both respiration and photosynthesis in the symbiotic sea-anemone Anemonia viridis. Mar Biol 123:715-722

Holst GRN, Glud M, Kuhl M, Klimant I (1997) A microoptode array for fine-scale measurement of oxygen distribution. Sensors and Actuators B 38-39:122-129

Holst GRN, Klimant I, Kühl M, Kohls O (2000) Optical microsensors and microprobes. In: Varney MS (ed) Chemical sensors in oceanography. Gordon and Breach Science Publishers, Amsterdam, p 143-188

Hooper GJ (2002) Effects of algal structural complexity on associated motile epifaunal communities. PhD thesis, University of London

Jørgensen BB, Des Marais DJ (1990) The diffusive boundary layer of sediments: oxygen microgradients over a microbial mat. Limnol Oceanogr 35(6):1343-1355

Kain JM, Svendsen P (1979) A note on the behaviour of Patina pellucida in Britain and Norway. Sarsia 38:25-30

Kaspar HF (1992) Oxygen conditions on surfaces of coralline red algae. Mar Ecol Prog Ser 81:97-100

King RJ, Schramm W (1976) Photosynthetic rates of benthic marine algae in relation to light intensity and seasonal variations. Mar Biol 37:215-222

Klimant I, Meyer V, Kuhl M (1995) Fiber-optic oxygen microsensors, a new tool in aquatic biology. Limnol Oceanogr 40:1159-1165

Kohler-Pink S, Kuhl M (2000) Microsensor studies of photosynthesis and respiration in larger symbiotic foraminifera. I. The physico-chemical microenvironment of Marginopora vertebralis, Amphistegina lobifera and Amphisorus hemprichii. Mar Biol 137:473-486

Editorial responsibility: Otto Kinne (Editor),

Oldendorf/Luhe, Germany
Krogh A (1919) The rate of diffusion of gases through animal tissues with some remarks on the coefficient of invasion. J Physiol 52:391-408

Lassen C, Bebout LE, Paerl HW, Jørgensen BB (1994) Microsensor studies of oxygen and light-distribution in the green macroalga Codium fragile. J Phycol 30:381-386

McAllen R, Taylor AC, Davenport J (1999) The effects of temperature and oxygen partial pressure on the rate of oxygen consumption of the high-shore rock-pool copepod Tigriopus brevicornis. Comp Biochem Physiol A 123: 195-202

Neira C, Sellanes J, Levin L, Arntz WE (2001) Meiofaunal distributions on the Peru margin: relationship to oxygen and organic matter availability. Deep-Sea Res I 48: 2453-2472

Nii CM, Muscatine L (1997) Oxidative stress in the symbiotic sea anemone Aiptasia pulchella (Calgren, 1943): contribution of the animal to superoxide ion production at elevated temperature. Biol Bull 192:444-456

Ploug H, Stolte W, Epping EHG, Jørgensen BB (1999) Diffusive boundary layers, photosynthesis, and respiration of the colony-forming plankton algae, Phaeocystis sp. Limnol Oceanogr 44(8):1949-1958

Pöhn M, Vopel K, Grünberger E, Ott J (2001) Microclimate of the brown alga Feldmannia caespitula interstitium under zero-flow conditions. Mar Ecol Prog Ser 210:285-290

Pouzand C, Tyrell RM (1999) Apoptosis, the role of oxidative stress and the example of solar radiation. Photochem Photobiol 70:380-390

Rijstenbil JW, Coelho SM, Eijsackers M (2000) A method for the assessment of light-induced oxidative stress in embryos of fucoid algae via confocal laserscan microscopy. Mar Biol 137:763-774

Rink S, Kühl M, Bijma J, Spero HJ (1998) Microsensor studies of photosynthesis and respiration in the symbiotic foraminifer Orbulina universa. Mar Biol 131:583-595

Salvato B, Cuomo V, Di Muro P, Beltramini M (2001) Effects of environmental parameters on the oxygen consumption of 4 marine invertebrates: a comparative factorial study. Mar Biol 138:659-668

Searcy-Bernal R (1996) Boundary layers and abalone postlarval culture: preliminary studies. Aquaculture 140:129-137

Stephenson TA, Zoond A, Eyre J (1934) The liberation and utilisation of oxygen by the population of rock-pools. J Exp Biol 11:162-172

Wenzhöfer F, Holby O, Kohls O (2001) Deep penetrating benthic oxygen profiles measured in situ by oxygen optodes. Deep-Sea Res I 48:1741-1755

Wiebe AH (1933) The effect of high concentrations of dissolved oxygen on several species of pond fishes. Ohio J Sci 33:110-126

Williams GA (1992) The effect of predation on the life histories of Littorina obtusata and Littorina mariae. J Mar Biol Assoc UK 72:403-416

Williams GA (1996) Seasonal variation in a low shore Fucus serratus (Fucales, Phaeophyta) population and its epiphytic fauna. Hydrobiologia 327:191-197

Zhang TC, Bishop PL (1994) Experimental-determination of the dissolved-oxygen boundary-layer and mass-transfer resistance near the fluid-biofilm interface. Water Sci Technol 20(11):47-58

Submitted: February 11, 2002; Accepted: September 17, 2002 Proofs received from author(s): November 12, 2002 